\title{
BMJ Open Ear for recovery: protocol for a prospective study on parent-child communication and psychological recovery after paediatric injury
}

\author{
Eva Alisic, ${ }^{1,2}$ Anna Barrett, ${ }^{1,2}$ Peter Bowles, ${ }^{1,2}$ Franz E Babl, ${ }^{2,3,4}$ \\ Rowena Conroy, ${ }^{5,6,7}$ Roderick J McClure, ${ }^{8}$ Vicki Anderson, ${ }^{5,6,7}$ Matthias R Mehl ${ }^{9}$
}

To cite: Alisic E, Barrett $A$, Bowles $\mathrm{P}$, et al. Ear for recovery: protocol for a prospective study on parentchild communication and psychological recovery after paediatric injury. BMJ Open 2015;5:e007393.

doi:10.1136/bmjopen-2014007393

- Prepublication history for this paper is available online. To view these files please visit the journal online (http://dx.doi.org/10.1136/ bmjopen-2014-007393)

Received 6 December 2014 Revised 5 January 2015 Accepted 7 January 2015
CrossMark

For numbered affiliations see end of article.

Correspondence to

Dr Eva Alisic;

eva.alisic@monash.edu

\section{ABSTRACT}

Introduction: One in six children who have been admitted to hospital with an injury develop persistent stress symptoms that put their development at risk. Parents play a crucial role in children's psychological recovery, however, it is unknown how specific parenting behaviours can help or hinder. We aim to describe the nature and quantity of parent-child communication after a child has been injured, and to examine how these interactions are related to children's psychological recovery.

Methods and analysis: We are conducting a prospective observational study among children aged 3-16 years, who have been admitted to a tertiary children's hospital with a serious injury. Data collection involves a naturalistic observation of spontaneous, everyday parent-child communication at home, shortly after discharge, and an assessment of children's psychological recovery at 6 weeks and 3 months postinjury. Main analyses comprise descriptive statistics, cluster analysis and analyses of variance.

Ethics and dissemination: This study has been approved by the Human Research Ethics Committee of the Royal Children's Hospital Melbourne (33103) and Monash University Human Research Ethics Committee (CF13/2515-2013001322). We aim to disseminate the findings through international peer-reviewed journals, international conferences and social media. Participants will be sent a summary of the overall study findings.

\section{INTRODUCTION}

Injuries sustained in childhood have physical and psychosocial consequences that can last for years or even throughout the lifespan. ${ }^{1}$ Stress reactions, such as nightmares, avoidance of places that remind them of the event, feelings of detachment and concentration difficulties, are common in children in the aftermath of serious injury. Winston $e t a l^{2}$ found that $88 \%$ of children admitted to hospital with an injury after a road traffic

\section{Strengths and limitations of this study}

- Fine-grained observation of parent-child interactions in daily life after paediatric injury.

- Attention to positive and negative predictors and outcomes.

- Novel, unobtrusive, ecological momentary assessment method.

- Transcription and coding of audio data is time and labour intensive.

accident reported one or more clinically significant symptoms of acute stress. For most children these symptoms are transient, however, about $15 \%$ develop persistent posttraumatic stress symptoms, which can impair functioning in cognitive, social, emotional and physical domains. ${ }^{3} 4$ Children and adolescents with post-traumatic stress disorder (PTSD) have been found to experience deficits in memory, attention and executive functioning. ${ }^{5}$ They show more emotion regulation difficulties, such as aggression, than children without PTSD $^{6}$ and experience difficulties maintaining relationships with friends. ${ }^{7}$ Post-traumatic stress is also related to increased use of general healthcare. ${ }^{8}$

Childhood injury is a specific and easily identifiable event which both constitutes a risk factor for physical and psychosocial difficulties, and places those at risk within a health system. This presents an opportunity to provide children and their families with information and support aimed at secondary prevention of post-traumatic stress and further consequences. Web-based psychoeducation and targeted brief early intervention for injured children and their parents have shown a modest effect ${ }^{9}$ and additional research has been called for to refine preventive approaches. In particular, these should be focused on parent-child processes. ${ }^{9} 10$ 
Parents have an active function in the immediate aftermath of an injury, including seeking emergency care, supporting their child through painful medical procedures, modelling a coping response, providing ongoing support and organising follow-up treatment. Parents have been shown to play a crucial role in children's post-trauma outcomes ${ }^{11}$ although this evidence has predominantly focused on the role of parental distress. ${ }^{3}$ More broadly, child anxiety and emotion regulation research has shown that parents can reinforce unfavourable coping strategies as well as active, prosocial coping in children. ${ }^{12-14}$ Finally, in-depth interviews showed that children attach great value to parental support after trauma. ${ }^{15}$ While it has been established that parents can play a crucial role in children's psychological recovery from serious injury, ${ }^{16}$ the next step is to examine what parents actually do that helps or hinders their child's recovery. Examining patterns of parent-child communication in daily life and associations between these and children's recovery will help in developing targeted and tailored interventions. ${ }^{9}$

The child medical traumatic stress domain has only recently moved towards a greater focus on parents, and studies in this vein have mostly utilised retrospective selfreport methodologies. Studies of parents' behaviour after a child's potentially traumatic experience via retrospective questionnaires or interviews are challenged by vulnerability to biases related to self-report, such as social desirability, recall bias, impression management, lack of self-knowledge and mental health status. ${ }^{17}$ In addition, many daily behaviours are so subtle and natural that people have difficulty identifying and reporting on them. Many of these challenges can be overcome using an observational approach that measures daily parent-child interactions in real life. In fact, the general developmental and anxiety literature includes many real-time observational studies of parents interacting with their children; however, these are mostly families from the general population or clinical samples that are not necessarily trauma exposed, participating in brief non-naturalistic observations (ie, families are given a particular task and are taped). ${ }^{18}$ In short, the traumatic stress literature has an evidence base that is on-topic but requires more detail and ecological validity to inform clinical practice, while the general developmental and anxiety literature has an evidence base that is detailed and rich but not trauma-specific nor in most cases entirely naturalistic.

A recently developed method, called the Electronically Activated Recorder (EAR), ${ }^{19}$ provides an opportunity to gather detailed, naturalistic observational data on parent-child communication in the aftermath of injury, without placing a high burden on participants. The EAR is an ecological momentary assessment method which captures snippets of acoustic information from participants' daily life. Ecological momentary assessment refers to the repeated sampling of participants' current behaviours and experiences in real time, in participants' natural environments. ${ }^{20}$ The EAR software operates on a small, unobtrusive device such as an iPod, and records snippets of ambient sound at preset random or regular intervals. It is one of the few ways to capture person-centred behavioural observational data in a natural environment. In particular, previous analyses showed that (1) after a short habituation period, the EAR operates unobtrusively and minimally interferes with participants' normal activities; (2) behavioural information can be reliably decoded from the sampled sounds; (3) behavioural aggregates based on 2 days of monitoring show good temporal stability; and (4) the periodic sampling pattern yields generalisable estimates of a person's daily behaviour. ${ }^{17}$ When used in combination with questionnaires, the EAR has the advantage of minimising method variance. ${ }^{17}$

\section{Research aim and objectives}

This study aims to describe the nature and quantity of parent-child communication after a child has been injured, and to examine how communication is related to children's psychological recovery, as well as other child, parent and family well-being variables. The findings will inform the development of clinical guidance to parents on how to help their child recover psychologically after injury. In particular, our main research objectives are to:

1. Characterise parent-child communication in the aftermath of children's serious injury;

2. Examine relationships between these parent-child communication patterns and children's psychological recovery.

\section{METHODS AND ANALYSIS}

\section{Study design}

The project is a prospective observational study. Children aged 3-16 years who have sustained a serious injury and their parents are enrolled at the Royal Children's Hospital Melbourne, Australia. This hospital is a tertiary children's hospital with a state-wide paediatric trauma centre. Data are collected at:

1. Baseline: In-hospital (T1a), we collect questionnaire data regarding demographics, injury characteristics, child acute stress and parent acute stress.

Shortly after discharge (T1b), we collect EAR recordings of 2 days of children's daily life at home.

2. Follow-up: At 6 weeks (T2) and 3 months (T3) postinjury we conduct structured telephone interviews regarding child and family outcomes.

\section{Eligibility criteria}

Families of children who have been hospitalised for at least $24 \mathrm{~h}$ due to an injury ${ }^{21}$ and are between 3 and 16 years of age are eligible, unless one or more of the following exclusion criteria apply: (1) the injury has been, or is suspected to have been, caused by child maltreatment or self-harm; (2) the family does not speak English in daily life (necessary for the coding of the 
EAR recordings); (3) the child has sustained a severe acquired brain injury (defined as a Glasgow Coma Scale $^{22}$ score $<9$ at hospital presentation) and experiences continued impaired cognitive functioning at the time of approach (as decided by medical staff); (4) the child is hospitalised for more than 4 weeks (we aim to measure parent-child communication within the first month pos-tinjury); or (5) the child's injury was secondary to an ongoing medical condition (eg, a fracture associated with osteogenesis imperfecta).

\section{Recruitment and procedures}

Potential participants are identified on a daily basis via the Royal Children's Hospital (RCH) Emergency Department and inpatient hospital databases. Initial contact with children and families is made via an in-hospital visit by a member of the research team and an RCH Trauma Service staff member. A brief description of the study and an information flyer are given to the child and family. If the family expresses interest in hearing more about the study, a member of the research team provides further information and documents the informed consent of participants and families. Subsequently, demographic and injury data are retrieved from the medical records. Children and parents fill out the baseline questionnaires at their earliest convenience and are provided with the EAR (an iPod Touch preprogrammed with the EAR software). Children wear the EAR during the first weekend after discharge. At 6 weeks, and again at 3 months after the injury, psychological outcomes are assessed through telephone interviews with parents and with children if they are old enough.

\section{Assessments}

Table 1 shows the assessments used in the study. The most important measures regard the observed parentchild communication and children's stress reactions.

\section{Primary measures}

\section{Child stress reactions}

Children's stress reactions are measured with the Children's Revised Impact of Event Scale (CRIES-13) ${ }^{23}$ and the Child PTSD Symptom Scale (CPSS), ${ }^{24}$ for children aged between 8 and 16 years. The CRIES-13 measures intrusion, avoidance and arousal symptoms with 13 items on a 4-point scale. Reliability and validity of the CRIES-13 have been shown in several studies. ${ }^{25}$ In one of our previous studies, $\alpha$ was $0.85 .^{26}$ The CPSS is a 24-item measure that can be used in the structured interview format and yields a continuous severity score, an impairment score, and a probable PTSD status. The scale has shown excellent internal consistency, test-retest reliability and convergent validity, ${ }^{24}$ and has been used successfully in medical child traumatic stress research. ${ }^{4}$ To include at least minimal data on younger children, parents of children of all age groups are asked to rate on a visual analogue scale how upset their child was directly after the event and how upset the child is at the time of assessment.

\section{Parent-child communication}

Families are loaned an EAR (a preprogrammed iPod Touch) to be used on the first feasible weekend after the child is discharged from the hospital. During two consecutive days, the injured child wears the EAR in a protective elastic belt on the outside of their clothes. Families are asked to keep a simple diary to identify the child's activities, who they are with, and any times the EAR is not worn by the child. The EAR records ambient sounds for $30 \mathrm{~s}$ every $5 \mathrm{~min}$, from 7:00 to 22:00, totalling about $10 \%$ of the time. The sampling pattern yields about 160 sound files ( 80 min of recording) per person per day. This has been found sufficient to derive reliable and valid data on people's unique communication patterns, ${ }^{17}{ }^{27}$ and by sampling only a fraction of the time, makes large observational studies feasible. The reliability,

Table 1 Ear for recovery study assessments

\begin{tabular}{|c|c|c|c|c|}
\hline Constructs & $\begin{array}{l}\text { Standardised } \\
\text { measures }\end{array}$ & $\begin{array}{l}\text { T1 } \\
\text { In-hospital } \\
\text { or at home }\end{array}$ & $\begin{array}{l}\text { T2 } \\
\text { Phone interview } \\
6 \text { weeks post- } \\
\text { injury }\end{array}$ & $\begin{array}{l}\text { T3 } \\
\text { Phone interview } \\
3 \text { months } \\
\text { post-injury }\end{array}$ \\
\hline $\begin{array}{l}\text { Demographics and injury } \\
\text { characteristics }\end{array}$ & AIS & $x$ & & \\
\hline Child stress reactions & CRIES-13, CPSS & $x$ & $x$ & $x$ \\
\hline Child social support & MSPSS & $x$ & & \\
\hline Child well-being & KIDSCREEN-27, SDQ & & $x$ & $x$ \\
\hline Parent-child communication at home & EAR & $\mathrm{x}$ & & \\
\hline Parental stress reactions & ASDS & $x$ & & \\
\hline Parental optimism & LOT-R & $x$ & & \\
\hline Parental self-efficacy & SDRP & $x$ & & \\
\hline Parental well-being & SF-36 & & $\mathrm{x}$ & $\mathrm{x}$ \\
\hline Family functioning & FACES-IV & $x$ & & \\
\hline
\end{tabular}


validity and unobtrusiveness of the EAR have been previously reported. ${ }^{172728}$ Transcription and coding of the EAR data are described below.

\section{Secondary measures}

\section{Demographics and injury characteristics}

Demographics, including family structure, are collected from the parents. Children's injury type (mechanism and general description) and severity (ISS; Injury Severity Score based on the Abbreviated Injury Scale) ${ }^{29}$ are retrieved from the trauma registry of the $\mathrm{RCH}$. Families are also asked whether one or both parents were present at the event that caused the injury, whether the child or a parent has been confronted with a traumatic event before, and whether the child or a parent has used mental healthcare services in the past 3 years.

\section{Child social support}

Children's perceived social support is measured with the Multidimensional Scale of Perceived Social Support (MSPSS). ${ }^{30}$ The 12-item measure reflects perceived support from family members, a special person and friends on a 7-point scale. Higher scores indicate more (perceived) social support. Reliability of the measure is high, as shown by a recent Australian study $(\alpha=0.90) .^{31}$

\section{Child well-being}

The KIDSCREEN-27 $7^{32}$ is used to assess the well-being of children aged $8-16$ years. It is a 27 -item instrument that covers five dimensions of quality of life on a 5-point scale: physical well-being, psychological well-being, autonomy and relationship with parents, peers and social support, and school environment. Validity and reliability are good. ${ }^{32}{ }^{33}$ In addition, children are asked to indicate on a visual-analogue scale how happy they felt a week before the injury happened, how happy they feel currently and how happy they expect to feel in 1 month's time. Further information regarding child well-being in all age groups is gathered via parents answering the Strengths and Difficulties Questionnaire $(\mathrm{SDQ})^{34}$ at T2 and T3. The SDQ is a brief behavioural screening questionnaire about 3-17-year-olds that is used often internationally. The reliability and validity of the SDQ have been described extensively. ${ }^{34}$ We use the Australian age-adapted versions (for 3-year-old; 410-year-old; and 11-17-year-old children).

\section{Parental stress reactions}

The Acute Stress Disorder Scale (ASDS) ${ }^{35}$ is used to assess parental acute stress reactions. The ASDS is a selfreport scale with 19 items that measure acute stress according to the Diagnostic and Statistical Manual of Mental Disorders, Fourth Edition, (DSM-IV) diagnostic criteria. ${ }^{36}$ Parents rate the extent to which they have experienced each symptom since the injury of their child on a 5-point scale. The scale is reliable $(\alpha=0.96)$ and has shown high sensitivity and specificity when compared with a diagnostic interview for acute stress disorder. ${ }^{35}$

\section{Parental optimism}

Parental optimism is measured with the revised Life Orientation Test-Revised (LOT-R). ${ }^{37}$ The measure has four 'filler' items that are not included in the score. The six remaining items measure participants' expectations about their future and their general sense of optimism on a 5-point scale. Reliability of the scale is acceptable $(\alpha=0.75)$ and its validity is well-researched and confirmed. ${ }^{38}$ In addition, parents indicate on a visual analogue scale how happy or unhappy they feel and how confident they feel that they will be able to cope with a stressful situation.

\section{Parental self-efficacy}

Parental self-efficacy is measured by the 15 efficacy-focused items of the Screener for the Development of a Response Posttrauma (SDRP). ${ }^{39}$ The scale measures participants' confidence in their ability to cope with a potentially traumatic event, with higher scores reflecting higher confidence (when the items referred to 'ill/injured' children we only retained the word 'injured').

\section{Parental well-being}

The Short-Form Health Survey $(\mathrm{SF}-36)^{40}$ is used to measure parental well-being. The SF-36 includes a single item measure of change in health status and a multi-item scale measuring each of the following eight health domains: physical functioning, role limitations due to physical health problems, bodily pain, general health, vitality, social functioning, role limitations due to emotional problems and mental health. Higher scores indicate higher levels of health and results can be divided into two aggregate scores: the physical component summary (PCS) and the mental component summary (MCS). Validity and reliability (PCS $\alpha=0.92$; MCS $\alpha=0.91$ ) of the measure have been demonstrated comprehensively. ${ }^{41}$

\section{Family functioning}

Family functioning is measured with the Family Adaptability and Cohesion Evaluation Scale IV (FACES-IV) $^{42}$ (parent report). The measure contains 84 items which assess high and low extremes of family cohesion and flexibility across six scales: balanced cohesion, balanced flexibility, enmeshed, disengaged, chaotic and rigid. Validity and reliability of the scales are good. ${ }^{43}$

\section{Data preparation and analysis}

Handling of the data will be split into two broad stages: (1) EAR data preparation involving transcribing and coding as well as reliability checking and (2) statistical analysis involving EAR data and questionnaire data.

\section{Stage 1: EAR data preparation}

EAR data preparation involves transcription and coding by trained research assistants receiving regular supervision. Each audio file (ie, each $30 \mathrm{~s}$ segment) will be prepared by at least two transcribers/coders, allowing for 
corrections and reliability analyses. We expect to handle over 15000 separate audio files.

\section{Transcribing}

Each audio file will be transcribed verbatim according to the guidelines of the computerised linguistic analysis programme called Linguistic Inquiry and Word Count (LIWC). ${ }^{44}$ The transcriptions will subsequently be aggregated and submitted to the LIWC software, which compares each word of a given text to a dictionary arranged into 74 categories (eg, family words, sadness words) and reports total numbers of words and proportions of overall word use falling into the specific word categories.

\section{Coding}

Audio file coding will focus on parent-child interactions, children's activities and behaviours, and the topics and tone of conversations. The coding is manualised: a standardised behavioural coding scheme-a system that details acoustically-detectible aspects of participants' social environment and interactions adapted from previous EAR studies- will be used. ${ }^{17}$ Each sound file will be coded for (1) interaction (eg, with how many people, who is talking); (2) activity (eg, watching TV, eating); (3) $\mathrm{mood} /$ health of the child (eg, laughing, crying, groaning from pain); (4) topic of conversation (eg, emotions/feelings, child rearing, injury related) and (5) tone of conversation (eg, 1=very negative to $7=$ very positive, with 4 being neutral; see figure 1 ). As an example, with regard to interaction we will indicate for each audio file whether the child is alone or not, and in case of the latter, whether the child is (1) interacting with one other person, (2) interacting with a group (ie, more than one person) or (3) nearby other people (eg, adults are talking among themselves a few metres away) but not interacting. If the child is interacting with one or more people, we will record the gender of the conversation partner(s).

\section{Reliability analyses}

The audio files will be coded by two research assistants, after which intercoder reliability will be calculated using
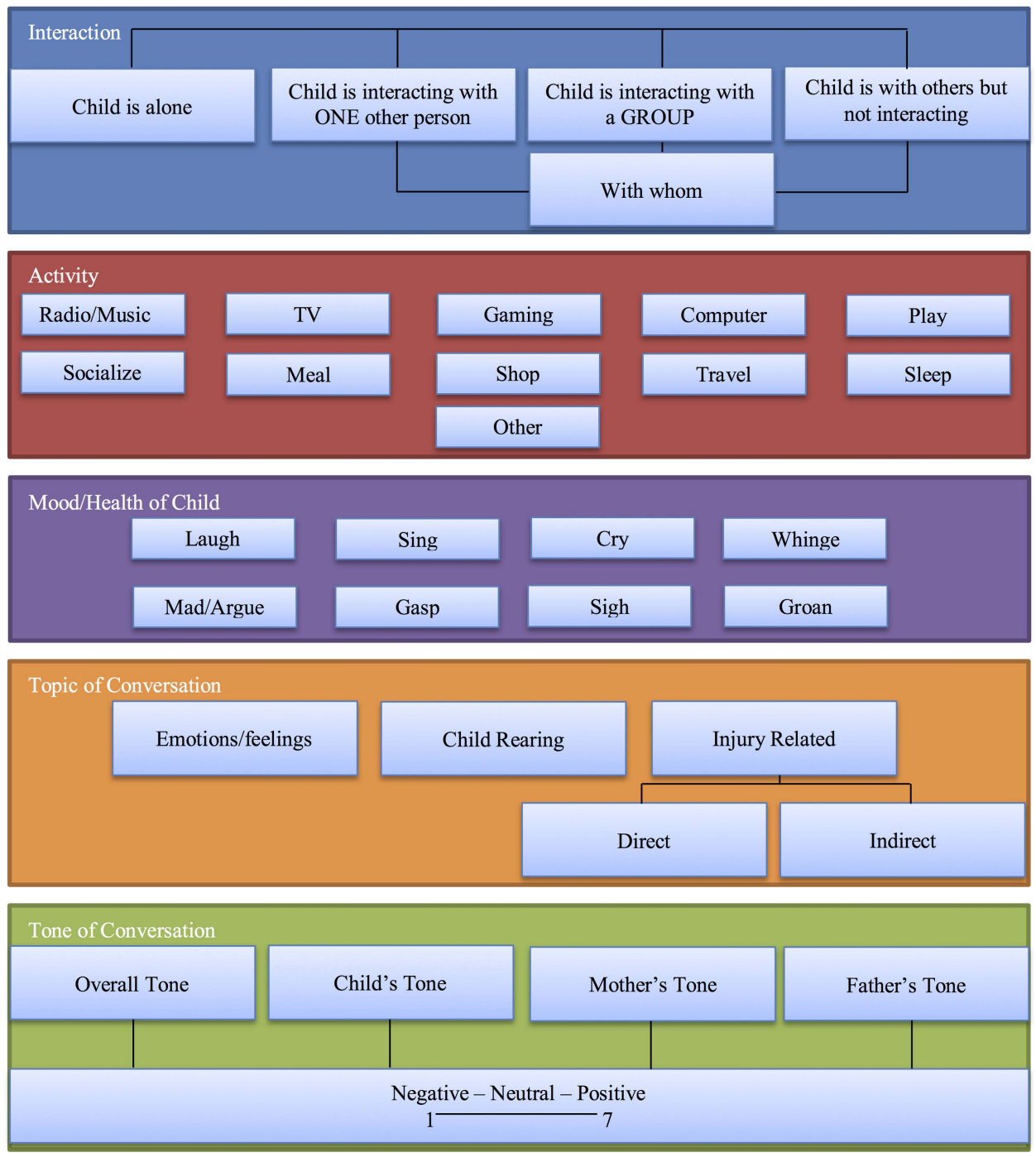

Figure 1 Standardised behavioural coding scheme. 
intraclass correlations. Previous EAR studies have reported good reliability after coder training. For example in a recent study by Robbins et $a l^{45}$ intraclass correlations for all coding categories ranged from 0.76 to 0.92 .

\section{Stage 2: Statistical analysis}

Our main questions regard (1) the nature and quantity of parent-child communication after paediatric injury and (2) the relation between parent-child communication and children's psychological recovery.

\section{Nature and quantity of parent-child communication}

First, we will describe the sample in terms of mean scores, SDs and proportions. For example, we will examine the proportion of time that the children are interacting with others, and to what extent this figure varies across families. Second, we will identify typologies of parent-child communication using two-step clustering. Cluster analysis organises data into groups, or clusters. In particular, two-step cluster analyses are used to reveal natural, homogeneous subgroups within a data set that may not otherwise be apparent. ${ }^{46}$ It is a person-centred approach that is particularly suited for new areas of research. Each family will be allocated to one cluster based on statistical similarity within clusters and dissimilarity between clusters. For example, clustering can take place based on the following four variables: (1) the amount of time that parents spend with their children in the aftermath of serious injury; (2) the proportion of interaction time in which the injury or its consequences is discussed; (3) the proportion of positive interactions; (4) the proportion of negative interactions. We will test stability of the generated clusters by repeating the procedure with the sample split in two. ${ }^{46}$ When a stable set of clusters has been generated, these will be interpreted and labelled by the research team. For example, a cluster could consist of 'withdrawn' parents (who may show low interaction, low injury discussion and low positive interactions).

\section{Associations with children's psychological recovery}

To understand which clusters of parenting behaviour are related to higher and lower levels of child post-traumatic stress, we will conduct analyses of variance. Parenting behaviour will be the independent variable (with the groups being compared as identified through the cluster analysis) and child post-traumatic stress score as the dependent variable (we will use the total symptom score of the CPSS). When significant, we will conduct multiple comparisons between groups with a Tukey-test.

\section{Secondary analyses}

In addition to these main analyses (clustering and associations with child stress outcomes), the data will allow for the quantitative and qualitative exploration of associations among communication factors and child, parent and family well-being.
Sample size

With regard to describing the nature and quantity of parent-child communication, means and proportions of behaviours can be described based on smaller sample sizes than inferential statistics. For clustering procedures, there is no generally accepted rule of thumb for minimum sample sizes. Formann advocates a sample size of at least $2^{\mathrm{m}}$, where $\mathrm{m}$ equals the number of clustering variables, suggesting that large sample sizes are not required (eg, 16 families if clusters were based on four variables) ${ }^{47}$ In order to relate communication characteristics to subsequent outcomes, the sample size requirements would increase with the number of variables involved. Previously published EAR studies have conducted data analyses with samples sizes of approximately 50 families. ${ }^{45}{ }^{48}$ As Finkel, ${ }^{49}$ indicate, in this type of research, it is important to balance type 1 and 2 errors. The larger the sample size, the more fine-grained the analyses can be. We expect a sample size of approximately 70 families and intend to make the data available for future studies in order to ensure sufficient future sample sizes.

\section{ETHICS AND DISSEMINATION}

Signed informed consent is obtained from all participating families. We aim to disseminate the results of the study through international peer-reviewed journals, international conferences and social media. Participants will be sent a thank you letter with a summary of the overall study findings. In addition, depending on approval from the institutions involved, we aim to make de-identified data from the study available for secondary analyses by external researchers.

\section{Particular ethical considerations associated with EAR research}

Mehl et $a l^{17}$ have previously highlighted a number of considerations specific to conducting EAR research such as issues of confidentiality when recording ambient sounds, and recording bystanders, discussed below.

\section{Recording bystanders}

The EAR records anything occurring in the acoustic environment of the child wearing it-anyone talking to, or talking near the child, including in public spaces, may be recorded. This means that some people recorded will not have provided written consent. As the recording takes place in the participant's natural environment shortly after hospital discharge, the majority of recordings take place in the home and involve immediate family members who are aware of the study. In order to ensure that bystanders are aware of the study, participants are asked to make the EAR visible by wearing it on the outside of their clothes with a 'RECORDING' label sewn onto the elastic belt. Participants and their parents are also advised to tell anyone coming into contact with the child over the recording weekend that the child is wearing the EAR. These steps, together, ensure that 
bystanders are aware of the potential of being recorded and therefore, in essence, passively consent to it. Along with the de-identification procedures described below, this makes it unlikely that the privacy rights of nonconsented people who are recorded are violated.

\section{Privacy and de-identification}

The EAR is programmed to record only a small fraction of a person's day. Sampling occurs for $30 \mathrm{~s}$ every $5 \mathrm{~min}$, allowing the EAR to "reliably extract basic behavioural information, yet (recordings) are short enough to capture only little contextualized personal information". ${ }^{17}$ While the brevity of the sound files protects participants' privacy to a certain extent, identifying information is still occasionally contained within them. Research team members involved in data preparation are trained to recognise and remove such information, including names, places and contact information. All identifying information is highlighted by researchers during the transcribing and coding process, and as each participant's recordings are transcribed and coded multiple times by separate researchers, there are multiple opportunities for identifying information to be detected. Any identifying information within audiorecordings is then deleted by silencing the relevant sections of the sound file. During transcription, any identifying words are replaced by functional codes. For example, 'Anna, can you turn the TV off?' becomes "(S1ster), can you turn the TV off?" Any written identifying information (eg, names written within the participant diaries) is blacked out after use.

\section{DISCUSSION}

While serious injury puts children's healthy development at risk, currently available early interventions have only been modestly successful in preventing the development of persistent post-traumatic stress symptoms. ${ }^{4}{ }^{9}$ With parents playing a central role in children's recovery, ${ }^{3} 16$ targeting parental support behaviour appears to be an important avenue for improving early interventions.

The Ear for Recovery study differs from previous research in its use of an unobtrusive naturalistic observation device to collect objective data in family situations that normally would go unstudied or would rely on selfreport. The outcomes of the current project will allow us to (1) better understand families' experiences after child injuries and therefore improve professional interactions with families; (2) indicate which parental behaviour may be helpful versus unhelpful, leading to specific recommendations for future early interventions (learning from the successful behaviour patterns while targeting the unsuccessful ones); (3) identify parents who may be in need of a tailored early intervention to help them support their child in the aftermath of a serious injury; and (4) further develop the EAR methodology as a diagnostic tool in child (mental) health research.

An important challenge of this study regards the time consuming and labour intensive process involved in handling the large volumes of audiodata. It is possible that as technology develops there will be the opportunity to make use of advanced speech recognition software, however, such software is not yet sophisticated enough to pick up on many of the subtleties that make up social interactions. A limitation of the current study is that we do not include an observation within the first few hours or day after the injury. It is possible that relevant parent-child interaction patterns take place in those first moments and become less frequent or prominent in the following days and weeks. In addition, an observation at the time points of the follow-ups was not feasible within the current study but would be of value for future research.

With the EAR methodology we will be able to provide a detailed characterisation of parent-child communication after serious injury. The current study aims to pave the way for better interventions to facilitate children's psychological recovery after serious injury. Implications may include exploring opportunities for use of the EAR methodology as a diagnostic measure in its own right and to inform other areas of child physical and mental health.

\section{Author affiliations}

${ }^{1}$ Monash Injury Research Institute, Monash University, Melbourne, Australia

${ }^{2}$ Emergency Research, Murdoch Childrens Research Institute Melbourne,

Australia

${ }^{3}$ Emergency Department, The Royal Children's Hospital, Melbourne, Australia ${ }^{4}$ Department of Paediatrics, The University of Melbourne, Melbourne, Australia ${ }^{5}$ Melbourne School of Psychological Sciences, The University of Melbourne, Melbourne, Australia

${ }^{6}$ Child Neuropsychology, Murdoch Childrens Research Institute, Melbourne, Australia

${ }^{7}$ Psychology Service, The Royal Children's Hospital, Melbourne, Australia

${ }^{8}$ Harvard Injury Control Research Center, Harvard School of Public Health, Boston, USA

${ }^{9}$ Department of Psychology, University of Arizona, Tucson, USA

Acknowledgements The authors would like to acknowledge the contributions of the Trauma Service and the nursing and medical staff of the Royal Children's Hospital Melbourne who are involved in the study. In particular, the authors would like to thank Helen Jowett, Cameron Palmer and Silvia Bressan.

Contributors $E A$ is the principal investigator of this study. $E A, A B, F E B, R C$, RJMC, VA and MM designed the study. EA, PB and AB drafted the manuscript. FEB, RC, RJMC, VA and MM provided feedback on the manuscript. All authors approved the manuscript.

Funding This study is supported by The Netherlands Organisation for Scientific Research (grant 446-11-021), Monash University (Larkins program) and the Victorian Government's Operational Infrastructure Support Program.

\section{Competing interests None.}

Ethics approval This study has been approved by the Human Research Ethics Committee of the Royal Children's Hospital Melbourne (study number 33103 ) and Monash University Human Research Ethics Committee (file number CF13/2515-2013001322).

Provenance and peer review Not commissioned; internally peer reviewed.

Open Access This is an Open Access article distributed in accordance with the Creative Commons Attribution Non Commercial (CC BY-NC 4.0) license, which permits others to distribute, remix, adapt, build upon this work noncommercially, and license their derivative works on different terms, provided the original work is properly cited and the use is non-commercial. See: http:// creativecommons.org/licenses/by-nc/4.0/ 


\section{REFERENCES}

1. Bell N, Kruse S, Simons RK, et al. A spatial analysis of functional outcomes and quality of life outcomes after pediatric injury. Inj epidemiol 2014;1:e16.

2. Winston FK, Kassam-Adams N, Vivarelli-O'Neill C, et al. Acute stress disorder symptoms in children and their parents after pediatric traffic injury. Pediatrics 2002;109:90.

3. Alisic E, Jongmans MJ, van Wesel F, et al. Building child trauma theory from longitudinal studies: a meta-analysis. Clin Psychol Rev 2011;31:736-47.

4. Kassam-Adams N, Garcia-Espana JF, Marsac ML, et al. A pilot randomized controlled trial assessing secondary prevention of traumatic stress integrated into pediatric trauma care. J Trauma Stress 2011;24:252-9.

5. Turley MR, Obrzut JE. Neuropsychological effects of posttraumatic stress disorder in children and adolescents. Can J Sch Psychol 2012;2:166-82.

6. Saigh PA, Yasik AE, Oberfield RA, et al. An analysis of the internalizing and externalizing behaviors of traumatized urban youth with and without PTSD. J Abnorm Psychol 2002;111:462-70.

7. Bryant B, Mayou R, Ehlers A, et al. Psychological consequences of road traffic accidents for children and their mothers. Psychol Med 2004;34:335-46.

8. Seng JS, Graham-Bermann SA, Clark MK, et al. Posttraumatic stress disorder and physical comorbidity among female children and adolescents: results from service-use data. Pediatrics 2005;116: e767-76.

9. Kassam-Adams N, Marsac ML, Hildenbrand A, et al. Posttraumatic stress following pediatric injury: update on diagnosis, risk factors, and intervention. JAMA Pediatr 2013;167:1158-65.

10. Berkowitz SJ, Stover CS, Marans SR. The child and family traumatic stress intervention: secondary prevention for youth at risk of developing PTSD. J Child Psychol Psychiatry 2011;52:676-85.

11. Scheeringa MS, Zeanah $\mathrm{CH}$. A relational perspective on PTSD in early childhood. J Trauma Stress 2001;14:799-815.

12. Dadds MR, Barrett PM, Rapee RM, et al. Family process and child anxiety and agression: an observational analysis. J Abnorm Child Psychol 1996;24:715-34.

13. Fivush R, Haden CA. Autobiographical memory and the construction of a narrative self: developmental and cultural perspectives. Psychology Press, 2003.

14. Salmon K, Bryant RA. Posttraumatic stress disorder in children. The influence of developmental factors. Clin Psychol Rev 2002;22:163-88.

15. Alisic E, Boeije HR, Jongmans MJ, et al. Children's perspectives on dealing with traumatic events. J Loss Trauma 2011;16: 477-96.

16. Morris A, Gabert-Quillen C, Delahanty D. The association between parent PTSD/depression symptoms and child PTSD symptoms: a meta-analysis. J Pediatr Psychol 2012;37:1076-88.

17. Mehl MR, Robbins ML, Deters FG. Naturalistic observation of health-relevant social processes: the electronically activated recorder methodology in psychosomatics. Psychosom Med 2012;74:410-17.

18. Lunkenheimer ES, Shields AM, Cortina KS. Parental emotion coaching and dismissing in family interaction. Soc Dev 2007; 16:232-48

19. Mehl MR, Pennebaker JW, Crow DM, et al. The Electronically Activated Recorder (EAR): a device for sampling naturalistic daily activities and conversations. Behav Res Methods Instrum Comput 2001;33:517-23.

20. Shiffman S, Stone AA, Hufford MR. Ecological momentary assessment. Annu Rev Clin Psychol 2008;4:1-32.

21. Kenardy JA, Spence SH, Macleod AC. Screening for posttraumatic stress disorder in children after accidental injury. Pediatrics 2006;118:1002-9.

22. Teasdale $\mathrm{G}$, Jennett B. Assessment of coma and impaired consciousness: a practical scale. Lancet 1974;2:81-3.

23. Children and War Foundation. Children's Revised Impact of Event Scale (CRIES-13). 2005. http://www.childrenandwar.org/measures/ children's-revised-impact-of-event-scale-8---cries-8/ies13/ (accessed 29 Jul 2014).

24. Foa EB, Johnson KM, Feeny NC, et al. The child PTSD symptom scale: a preliminary examination of its psychometric properties. J Clin Child Psychol 2001;30:376-84.
25. Perrin S, Meiser-Stedman R, Smith P. The Children's Revised Impact of Event Scale (CRIES): validity as a screening instrument for PTSD. Behav Cogn Psychother 2005;33:487-98.

26. Alisic E, Kleber RJ. Measuring posttraumatic stress reactions in children: preliminary validation of the children's responses to trauma inventory. J Child Adolesc Trauma 2010;3:192-204.

27. Mehl MR, Holleran SE. An empirical analysis of the obtrusiveness of and participants' compliance with the Electronically Activated Recorder (EAR). Eur J Psychol Assess 2007;23:248-57.

28. Mehl MR, Pennebaker JW. The sounds of social life: a psychometric analysis of students' daily social environments and natural conversations. J Pers Soc Psychol 2003;84:857-70.

29. Gennarelli TA, Wodzin E. The abbreviated injury scale 2005. Des Plaines, IL: Association for the Advancement of Automotive Medicine, 2005.

30. Zimet GD, Dahlem NW, Zimet SG, et al. The multidimensional scale of perceived social support. J Pers Assess 1988;52:30-41.

31. Ellis AA, Nixon RD, Williamson P. The effects of social support and negative appraisals on acute stress symptoms and depression in children and adolescents. Br J Clin Psychol, 2009;48(Pt 4):347-61.

32. Ravens-Sieberer U, Gosch A, Abel T, et al. Quality of life in children and adolescents: a European public health perspective. Soz Praventivmed 2001;46:294-302.

33. Ravens-Sieberer U, Auquier P, Erhart M, et al. The KIDSCREEN-27 quality of life measure for children and adolescents: psychometric results from a cross-cultural survey in 13 European countries. Qual Life Res 2007;16:1347-56

34. Goodman A, Goodman R. Strengths and difficulties questionnaire as a dimensional measure of child mental health. J Am Acad Child Adolesc Psychiatry 2009;48:400-3.

35. Bryant RA, Moulds ML, Guthrie R. Acute stress disorder scale: a self report measure of acute stress disorder. Psychol Assess 2000;12:61-8.

36. American Psychiatric Association. Diagnostic and statistical manual of mental disorders. 4th edn. Text revision. Washington: American Psychiatric Association, 2000.

37. Scheier MF, Carver CS, Bridges MW. Distinguishing optimism from neuroticism (and trait anxiety, self-mastery, and self-esteem): a re-evaluation of the life orientation test. J Pers Soc Psycho 1994:67:1063-78.

38. Terrill AL, Ruiz JM, Garofalo JP. Look on the bright side: do the benefits of optimism depend on the social nature of the stressor? J Behav Med 2010;33:399-414.

39. Cirilli C. Traumatic stress responses in mothers and fathers to paediatric intensive care treatment: the role of the beliefs. PCOM Psychology Dissertations, 2012. http://digitalcommons.pcom.edu/cgi/ viewcontent.cgi?article $=1214 \&$ context=psychology dissertations (accessed 25 Jul 2014)

40. Ware JE Jr, Sherbourne CD. The MOS 36-item short-form health survey (SF-36): II. Conceptual framework and item selection. Med Care 1992:473-83.

41. Ware JE Jr. SF-36 Health Survey (Version 1.0) for use in Australia. Australian Health Outcomes Collaboration (AHOC). http://ahsri.uow. edu.au/content/groups/public/@web/@ chsd/documents/doc/ uow132411.pdf (accessed 29 Jul 2014)

42. Olson DH, Sprenkle DH, Russell CS. Circumplex model of marital and family systems: I. Cohesion and adaptability dimensions, family types, and clinical applications. Fam process 1979;18:3-28.

43. Olson D. FACES IV and the circumplex model: validation study. J Marital Fam Ther 2011;37:64-80.

44. Pennebaker JW, Francis ME, Booth RJ. Linguistic inquiry and word count (LIWC) [Computer software]. Austin, TX: LIWC, 2007.

45. Robbins ML, López AM, Weihs KL, et al. Cancer conversations in context: naturalistic observation of couples coping with breast cancer. J Fam Psychol 2014;28:380-90.

46. Mooi E, Sarstedt M. A concise guide to market research: the process, data, and methods using IBM SPSS Statistics. London: Springer, 2011.

47. Formann AK. Die latent-class analyse: einführung in die theorie und anwendung, Beltz, 1984.

48. Slatcher RB, Robles TF. Preschoolers' everyday conflict at home and diurnal cortisol patterns. Health Psychol 2012;31:834-8.

49. Finkel EJ, Eastwick PW, Reis HT. Best research practices in psychology: illustrating epistemological and pragmatic considerations with the case of relationship science. J Pers Soc Psychol 2015;108:275-97. 